L.N. Ovcharova

National Research University Higher School of Economics, Moscow, Russia

D.O. Popova

National Research University Higher School of Economics, Moscow, Russia

A.M. Rudberg

National Research University Higher School of Economics, Moscow, Russia

\title{
Decomposition of Income Inequality in Contemporary Russia $^{6}$
}

Abstract. Over the last 25 years, Russia has passed from the group of countries distinguished by low levels of income inequality to the group distinguished by high ones. The macroeconomic analysis shows that this process is due to the differences in salaries, the weak equalizing effect of social transfers and new sources of income such as the income from property and of business activity. We have a poor understanding of the factors determining this inequality at the household level so far. Decomposition of equivalised household expenditure inequality into inter- and intra-groups using cross-sectional data (RLMS-HSE, 1994-2014) shows that during the whole research period one of the most significant factors of intergroup inequality is region of residence. During periods of high economic growth the significance of education and intensity of employment increased in intergroup inequality; however, during the period of economic stagnation the intergroup differentiation of educational potential began to decrease. Despite the important population policy aimed to increase the birth rate, children in families have become the most significant factor of intergroup inequality for the last years. A regression analysis of the determinants of inequality, which allows us to estimate the contribution of each factor to the model dispersion of per capita expenditure allows us to draw the conclusion that meritocratic factors explain a majority of observed inequality. The contribution of the child-burden factor to total inequality did not change during the past ten years, and at the same time, the inequality-decreasing effect of the presence of pensioners in households has continuously increased.

Keywords: income and wages inequality, wealth and poverty, human capital.

JEL Classification: D6, I3, J3, N00, P36.

\section{В.Е. Гимпельсон ЦеТИ НИУ ВШЭ, Москва}

\section{Отраслевые сдвиги и межотраслевое неравенство}

Аннотация. В статье обсуждается вопрос о влиянии отраслевого деления на неравенство в заработной плате в России в начале XXI в. Это влияние определяется отраслевой структурой занятости, уровнем отраслевых премий и внутриотраслевой дифференциацией уровней заработной платы. Расчеты, основанные на различных данных Росстата, показывают, что данные факторы способствовали снижению неравенства. В отраслевой структуре сокращалась доля в общей занятости отраслей, имеющих самые высокие и самые низкие заработные платы, тем самым сжимая с обеих сторон распределение заработных плат. Уровни оплаты в отраслях-лидерах и отраслях- аутсайдерах приближались к средним по всей экономике. В то же время внутриотраслевое неравенство, измеряемое коэффициентом Джини, также сокращалось. Наблюдаемая динамика межотраслевого неравенства в среднесрочной перспективе может сохраниться. Снижение мировых цен на сырье и энергоносители будет отрицательно влиять на возможности соответствующих предприятий повышать оплату труда, тем самым сжимая относительные заработные платы. То же самое, по-видимому, будет происходить и в финансовом секторе, на который серьезно повлиял текущий кризис. Если повышающее давление на заработную плату в бюджетных отраслях не исчезнет, то относительные заработные платы в них будут расти, а доля в занятости - падать, что также создаст выравнивающий эффект.

Ключевые слова: заработная плата, неравенство, межотраслевая дифференииаиия. Классификация JEL: J21, J31.

\footnotetext{
6 The publication has been prepared with the financial assistance of the Center for Basic Research of National Research University Higher School of Economics.
} 


\section{Введение}

Дифференциация заработной платы на рынке труда складывается под воздействием множества разнообразных факторов. Среди них - и индивидуальные характеристики работников (более образованные, более опытные и более мотивированные, как правило, зарабатывают больше), и характеристики рабочих мест (более производительные предприятия обычно платят больше). Одна из важных характеристик рабочих мест - принадлежность к определенному виду деятельности $(\text { отрасли })^{1}$. Согласно неоклассической экономической теории на конкурентном рынке труда при тщательном контроле всех факторов (включая неслучайный отбор работников в профессии и виды деятельности) характеристики рабочих мест (включая отраслевую принадлежность) не должны влиять на уровень оплаты труда. Однако в реальной жизни отраслевая принадлежность воздействует на этот показатель и межотраслевая дифференциация, как правило, имеет место. Чем менее конкурентный рынок, тем выше могут быть отраслевые премии.

В этой короткой статье для «Горячей темы» я рассматриваю только один аспект формирования дифференциации в заработной плате - влияние укрупненных отраслей (видов деятельности).

Следует отметить, что отраслевая принадлежность, в свою очередь, связана со многими другими факторами зарплатообразования и выделить чистый вклад отраслевого фактора, очищенный от прочих влияний и эффектов отбора и самоотбора в отрасль, - задача сложная, и ее решение выходит далеко за рамки данной работы. Ее цель - скромная: в рамках данного обсуждения показать основные тенденции в структуре занятости в 2000-2014 гг. и их влияние на неравенство в оплате труда.

Почему эта цель имеет смысл? Потому что в России сложилась значительная межотраслевая дифференииачия, и часто в политических дискуссиях именно она считается основным фактором российского неравенства. Отсюда могут следовать малообоснованные выводы о том, что в одних отраслях надо заработки понизить, а в других - повысить.

Я попытаюсь ответить на три основных вопроса. Во-первых, какова межотраслевая дифференциация в средних заработных платах? Во-вторых, каков удельный вес отдельных отраслей в общей занятости? Чем ближе оплата труда в данной отрасли к средней по экономике и чем меньше доля этой отрасли в общей занятости, тем меньше ее вклад в межотраслевое неравенство. И наоборот: большая по численности занятых отрасль, которая платит своим работникам намного больше (или намного меньше) всех остальных, будет во многом формировать общую картину неравенства. И, наконец, в-третьих, как различается и как меняется во времени внутриотраслевая дисперсия заработных плат? Таким образом, сокращение дифференциации может идти по трем направлениям.

В соответствии с этой логикой я вначале вкратце рассмотрю динамику отраслевых сдвигов в занятости, затем - динамику относительной оплаты труда, и наконец - ее внутриотраслевую вариацию.

Прежде чем обсуждать отраслевые сдвиги за период 2000-2014 гг., стоит вкратце остановиться на динамике основных макропоказателей (рис. 1). За этот период ВВП вырос почти на $80 \%$, а общая численность занятых всего лишь на $5 \%$. Это можно считать наглядным проявлением әкономического роста, не создающего рабочие места (jobless growth). Тaкая низкая эластичность занятости от выпуска (вне зависимости от фазы цикла) является хронической особенностью российского рынка труда - она наблюдалась на протяжении всего постсоветского периода и имеет институциональную природу (Gimpelson, Kapeliushnikov, 2013; OECD, 2011). Понятно, что при этом динамика агрегированной производительности почти полностыю определяется динамикой выпуска, а не изменениями затрат труда.

Однако стабильность агрегированного показателя занятости не означает отсутствия изменений в занятости, внутри которой

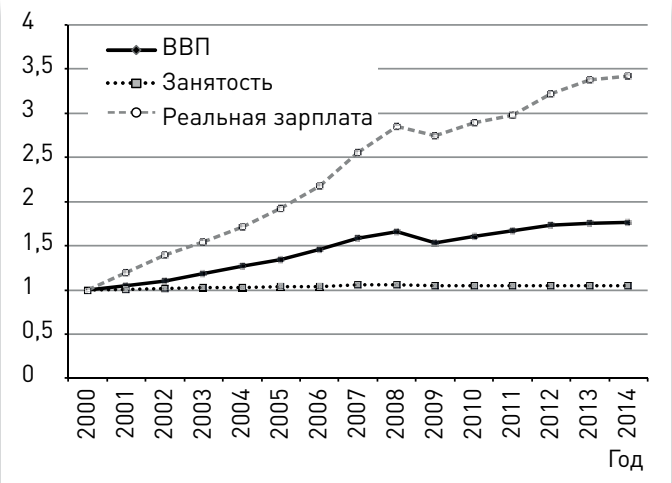

Рис. 1

Динамика ВВП, занятости и реальной заработной платы, 2000-2014 ге., 2000 г. = 1

Источник: по данным Росстата.

${ }^{1}$ В данной статье я использую понятия «отрасль» и «вид» деятельности как синонимы. 
возможны глубинные структурные изменения. Авторы многочисленных исследований отмечают глубокуютрансформацию различных структур занятости в России за последние 25 лет - профессиональной, образовательной, с точки зрения типов трудовых контрактов и т.п. (Российский работник..., 2011). Эти сдвиги имеют, в частности, ярко выраженную отраслевую специфику.

\section{1. Динамика отраслевой занятости}

На рис. 2 показаны основные изменения, происшедшие в структуре занятости по укрупненным видам деятельности, за период 2000-2014 гг.

Отметим прежде всего несколько видов деятельности, доли которых в общей занятости резко сократились. Так, удельный вес сельского хозяйства сократился на 4,7 п.п. (с 14,1 до 9,4\%), или на одну треть. Аналогично по масштабу и снижение размера обрабатывающего сектора (на 4,5 п.п. - с 19,1 до 14,6\%). Суммарное сжатие этих двух отраслей превышает 9 п.п. Оба вида деятельности производят торгуемые (на конкурентном рынке) товары.

Сокращение также испытали образование и здравоохранение, но масштаб сжатия был намного меньше - суммарно они потеряли 1,4 п.п. в структуре занятости. Можно также отметить стагнацию занятости в добывающих отраслях (-0,1 п.п.), лидирующих по величине заработной платы. И хотя масштаб сокращения невелик, но оно происходило на фоне значительного роста выпуска в этих отраслях, которые на протяжении периода были бенефициарами и мировой ценовой конъюнктуры, и как следствие - масштабных инвестиций. Эти отрасли являются высококапиталоемкими, но используют незначительные объемы труда.

А в каких отраслях наблюдался компенсирующий рост занятости? Услуги и строительство-трудоемкие, но относительно менее капиталоемкие сферы деятельности. Трудоемкий также весь сектор торговли (можно добавить к нему и отрасль «Гостиницы и рестораны»). Если в 2000 г. на его долю приходилось 15,2\% всех (основных) рабочих мест, то в 2014 г. - уже 20,3\%! Таким образом, прибавка составила 5,1 п.п. и компенсировала больше половины (55\%) суммарного сокращения в сельском хозяйстве и в обрабатывающих производствах.

Удельный вес строительства увеличился на 1,8 п.п., отрасли, связанной с операциями с недвижимостью и предоставлением услуг, на 1,7 п.п. и финансового сектора - на 1 п.п. Эти отрасли производят неторгуемые блага, ориентированные на местные рынки и не участвующие в глобальной конкуренции.

Описанные выше изменения шли более быстрым темпом до 2008 г. на фоне экономического роста, затем имела место непродолжительная пауза во время кризиса 2008-2009 гг.,

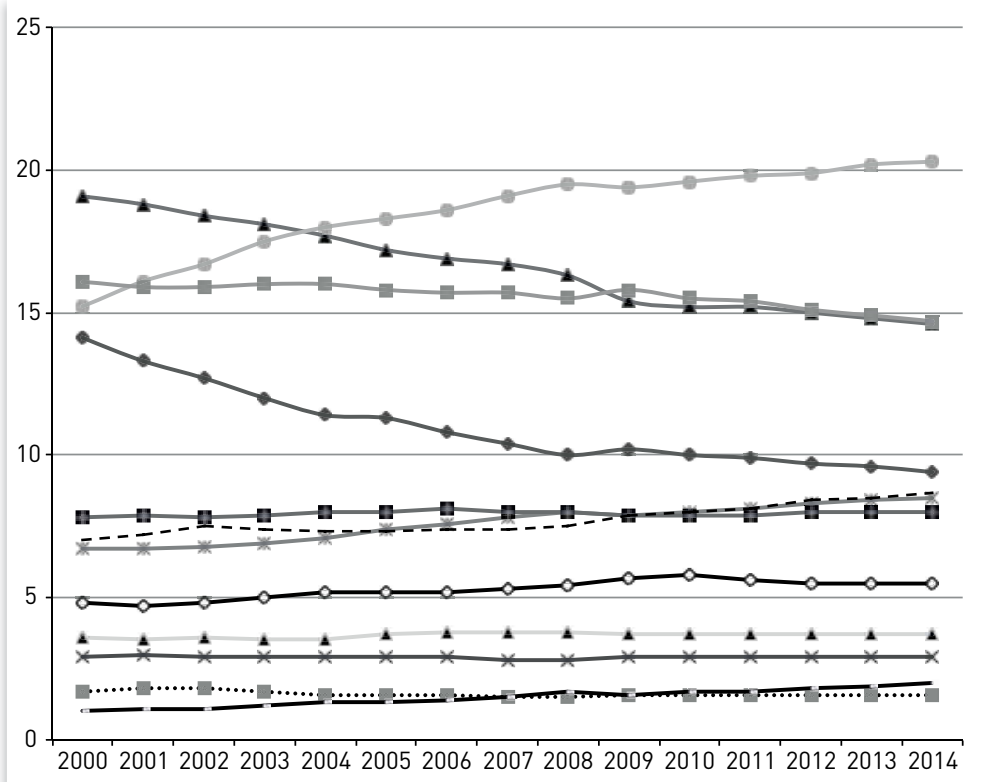

\begin{tabular}{|c|c|}
\hline$\rightarrow$ & $\begin{array}{l}\text { Сельское хозяйство, } \\
\text { рыболовство } \\
\text { и лесное хозяство }\end{array}$ \\
\hline$\cdots \cdot \cdot$ & $\begin{array}{l}\text { Добыча полезных } \\
\text { ископаемых }\end{array}$ \\
\hline- & $\begin{array}{l}\text { Обрабатывающие } \\
\text { производства }\end{array}$ \\
\hline 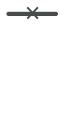 & $\begin{array}{l}\text { Производство } \\
\text { и распределение } \\
\text { электроэнергии, } \\
\text { газа и воды }\end{array}$ \\
\hline$\rightarrow$ & Строительство \\
\hline & $\begin{array}{l}\text { Торговля, бытовое } \\
\text { обслуживание, } \\
\text { гостиницы и рестораны }\end{array}$ \\
\hline- & Транспорт и связь \\
\hline-- & Финансы \\
\hline--- & $\begin{array}{l}\text { Операции } \\
\text { с недвижимостью }\end{array}$ \\
\hline$\infty$ & $\begin{array}{l}\text { Государственное } \\
\text { управление }\end{array}$ \\
\hline$\rightarrow$ & $\begin{array}{l}\text { Образование } \\
\text { и здравоохранение }\end{array}$ \\
\hline- & Другие услуги \\
\hline
\end{tabular}

Рис. 2

Изменения в структуре занятости по укрупненным видам деятельности, 2000-2014 ге., \%

Источник: по данным Росстата. 
после чего изменения вновь ускорились, но уже на фоне наступившей посткризисной стагнации. Однако основная направленность этих изменений все время была одной и той же. Занятость в отраслях, производящих торгуемые товары, сокращалась, а в производителях неторгуемых услуг росла. При этом значительная доля реаллокации определялась динамикой занятости лишь в четырех отраслях: двух основных «ликвидаторах» (сельском хозяйстве и обрабатывающих производствах) и двух основных «созидателях" рабочих мест (торговле и строительстве). Хотя для более строгих выводов требуются дополнительные исследования, складывается стойкое впечатление, что изменение отраслевой структуры занятости слабо зависело от темпов экономического роста и имело иные глубинные и, по-видимому, институциональные детерминанты.

\section{2. Динамика отраслевых заработных плат}

Статистика говорит о значительной динамике как абсолютной, так и относительной заработной платы. В течение 2000-2008 гг. (т.е. после начала быстрого роста углеводородных цен) реальная заработная плата росла со среднегодовым темпом выше 13\%. Кризис 2009 г. прервал этот невероятный рост, и уровень реальной заработной платы упал на 4,5\%, но затем рост вернулся, хотя и замедлился (в среднем около 4\% в период с 2009 по 2014 г.). В целом же в 2014 г. реальная заработная плата была в 3,5 раза выше, чем в 2000 г.

Динамика заработной платы заметно различалась по отраслям (рис. 3). Быстрее всего заработная плата росла в бюджетном секторе и сельском хозяйстве, медленнее всего - в добывающих отраслях и финансах. Другими словами, она росла быстрее в отраслях с самой низкой оплатой и заметно медленнее - в отраслях с самой высокой. Рост в обрабатывающей промышленности был близким к средним значениям. В итоге межотраслевые различия в оплате труда должны были сокращаться.

Разная динамика заработной платы в основных видах деятельности вела к изменению относительных заработных плат и к изменению общей картины межотраслевой дифференциации. На рис. 4 показано, как изменилось отношение средней заработной платы в отраслях к средней по всей экономике за период с 2005 по 2014 г.

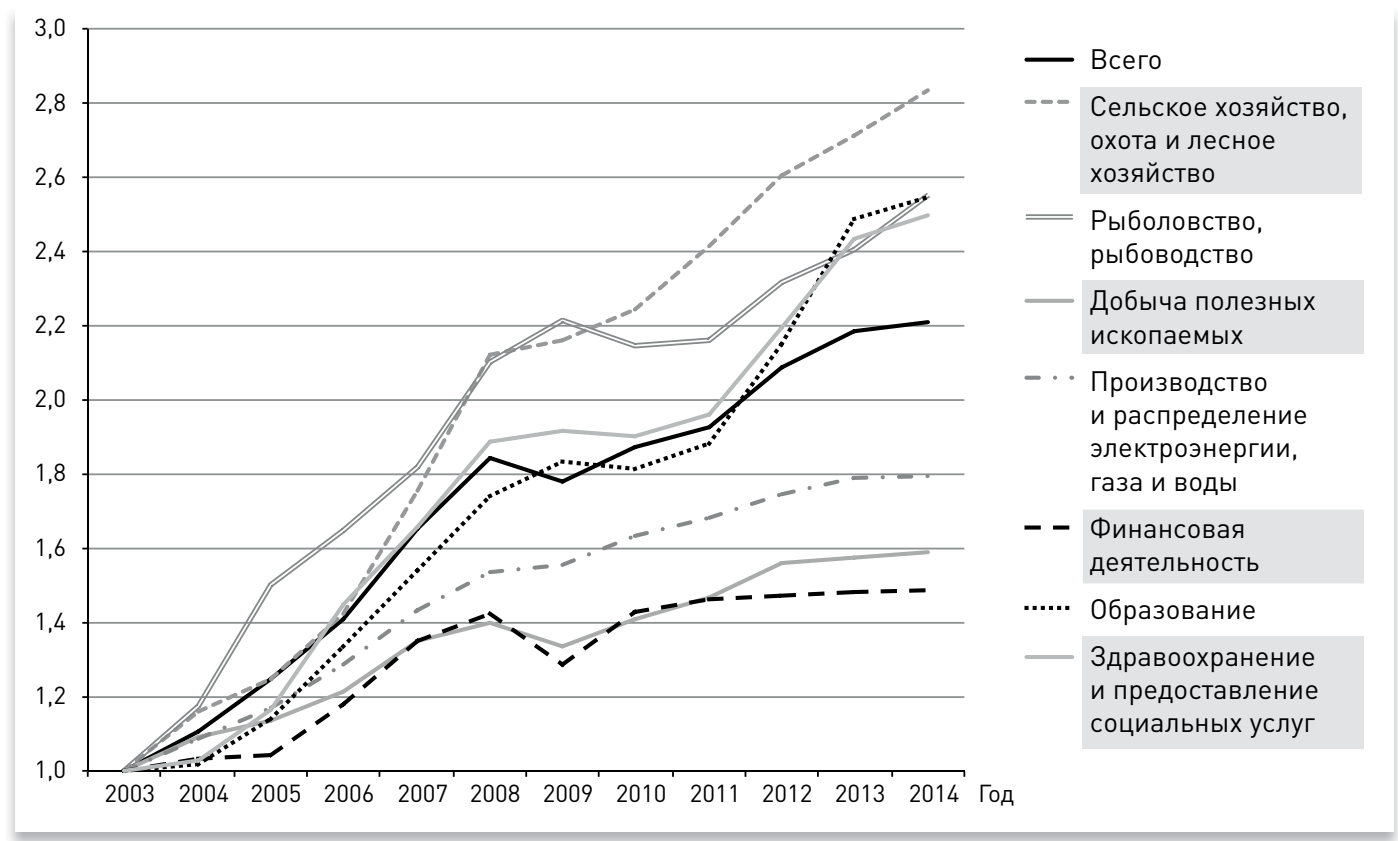

Pис. 3

Рост реальной заработной плать в среднем по әкономике и некоторых видах деятельности, 2000-2014 г2. Источник: по данным Росстата.

Примечание. Для наглядности показаны только виды деятельности с наиболее быстрым (четыре вида) и наиболее медленным (3 вида) ростом реальной заработной платы. В остальных видах деятельности темп роста был близким к среднему. 


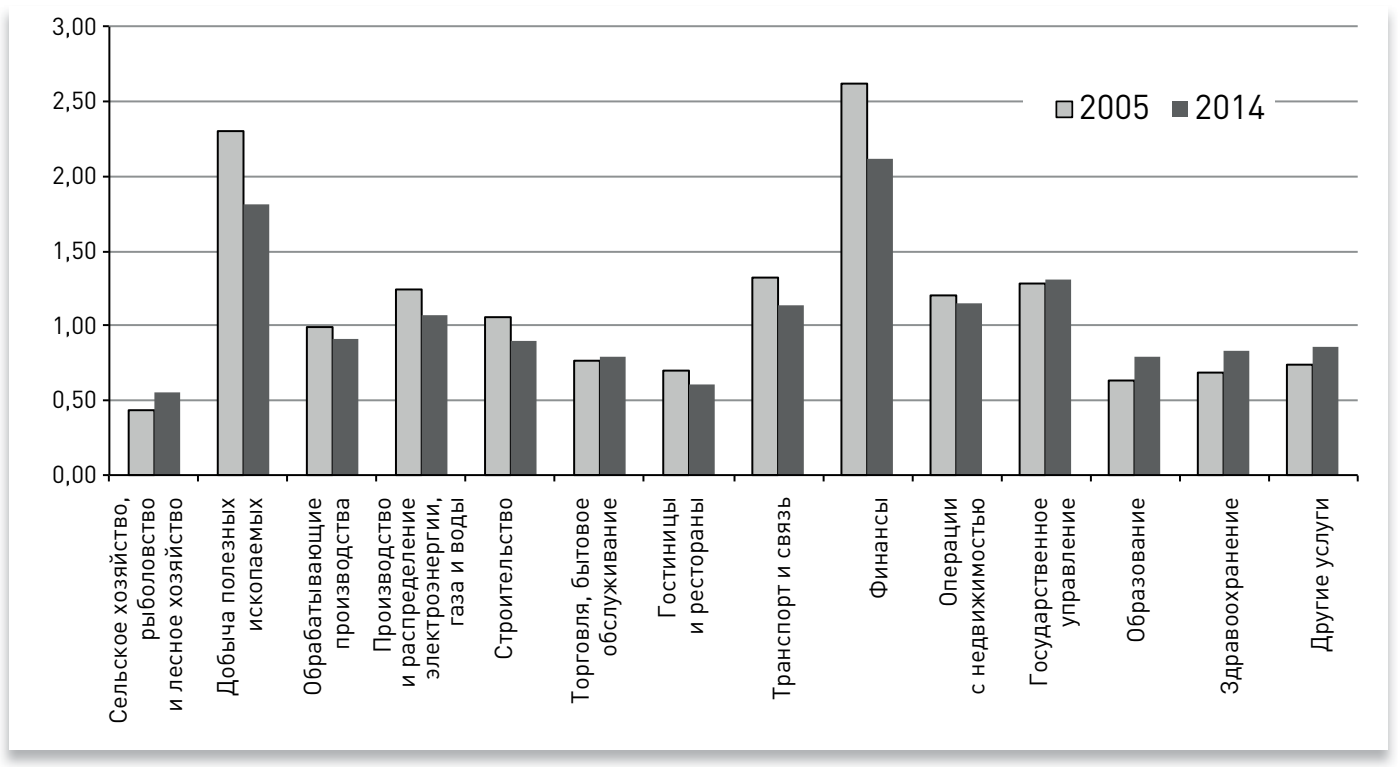

Puc. 4

Относительнъе заработнъе плать по видам деятельности (\% к средней по экономике)

Источник: по данным Росстата.

За 10 лет различия между лидерами и аутсайдерами по уровню оплаты труда заметно сократились. В 2005 г. средняя оплата труда в сельском хозяйстве - отрасли с наименьшей оплатой - составляла $44 \%$, а в 2014 г. $56 \%$ от средней по экономике. В образовании и здравоохранении соотношения увеличились с 63 и $69 \%$ до 80 и $83 \%$ соответственно. Приближение к средней наблюдалось и на противоположном полюсе - высоких отраслевых заработных плат. Явными аутсайдерами здесь являются добывающие отрасли и финансы, но в добывающих отраслях соотношение со средней сократилось с 230 до 180\%, в финанcax - с 263 до 211\%. Таким образом, налицо сплющивание распределения с обеих сторон конвергенция средних отраслевых заработных плат. В итоге коэффициент вариации средних заработных плат по укрупненным видам деятельности снизился с 63 до 44\%.

Изменения в отраслевой структуре занятости и в отраслевых относительных заработных платах меняют межотраслевое распределение фонда оплаты труда. Доля отраслей, в которых заработная плата близка к средней по экономике, растет, а доля крайних сокращается. Это должно работать в пользу снижения общей дифференциации в оплате труда.

\section{3. Дифференциация оплаты: влияние отрасли на индивидуальную заработную плату}

Представленные выше данные характеризуют средние заработные платы по отраслям, но не учитывают значительные структурные различия в составе занятых. При этом структура занятых по полу, возрасту, образованию, квалификации, отработанному времени и т.п. сильно варьирует. Поэтому различия в средних могут отражать не столько различия в уровнях оплаты труда, сколько различия в основных производительных характеристиках работников, занятых в разных отраслях.

Для того чтобы учесть эти различия и получить более адекватные оценки собственно отраслевых влияний на заработную плату, можно использовать стандартную әконометрическую технику, заключающуюся в оценивании уравнения заработной платы (так называемого Минцеровского уравнения). В это уравнение в качестве регрессоров включаются отраслевые дамми-переменные. Оценки коэффициентов характеризуют влияние отрасли на заработную плату, при том что индивидуальные характеристики работников контролируются.

Я оцениваю такое уравнение, используя данные «Обследования заработной платы по профессиям» за 2005, 2007, 2009, 2011 и 2013 г. (в другие годы обследование не проводилось). Это обследование имеет большую выборку (около 800 тыс. человек), но ограничено крупными и средними предприятиями и при этом не включает три отрасли (сельское хозяйство, 
финансы и государственное управление). Такое ограничение выборки заставляет нас осторожно интерпретировать результаты, ограничивая выводы корпоративным сектором $^{2}$. Однако нас интересуют не столько сами оценки, сколько их динамика во времени.

В качестве контрольных индивидуальных переменных в уравнение включены пол, возраст, образование, отработанное время, форма собственности предприятия и регион. Обрабатывающая промышленность принята в качестве базы сравнения. Полученные значения коэффициентов пересчитаны в эффекты, выраженные в процентах.

На рис. 5 представлена эволюция влияний (эффектов) отрасли на заработную плату. Значения по вертикальной оси показывают превышение заработной платы в данной отрасли по сравнению с обрабатывающими производствами (т.е. отраслевые отдачи). Показатели отдачи постепенно сближаются, и конвергенция отраслей с наименьшей оплатой труда (Образование (раздел М);
Здравоохранение (раздел N); Деятельность в области культуры (92)) проявляется весьма отчетливо.

Из графиков на рис. 6 следует, что для обследуемых отраслей имеет место конвергенция отраслевых отдач (эффектов). В нижней части отраслевого распределения она ускорилась между 2011 и 2013 г. Это является, по-видимому, следствием принятых мер, направленных на повышение заработной платы бюджетникам, предусмотренных Майскими (2012 г.) Указами Президента РФ, а также влиянием неоднократных повышений МРОТ на оплату в сельском хозяйстве отрасли с наименьшим уровнем оплаты. Если в 2005 г. принадлежность к бюджетным отраслям - образованию и здравоохранению - давала штраф более 40\%, то к 2013 г. он снизился до $30 \%$. Сократилась и премия за работу в добывающих отраслях - с 40 до, примерно, 33\%. Мы также видим стягивание всех прочих отраслей к горизонтальной оси (соответствующей обрабатывающим производствам).

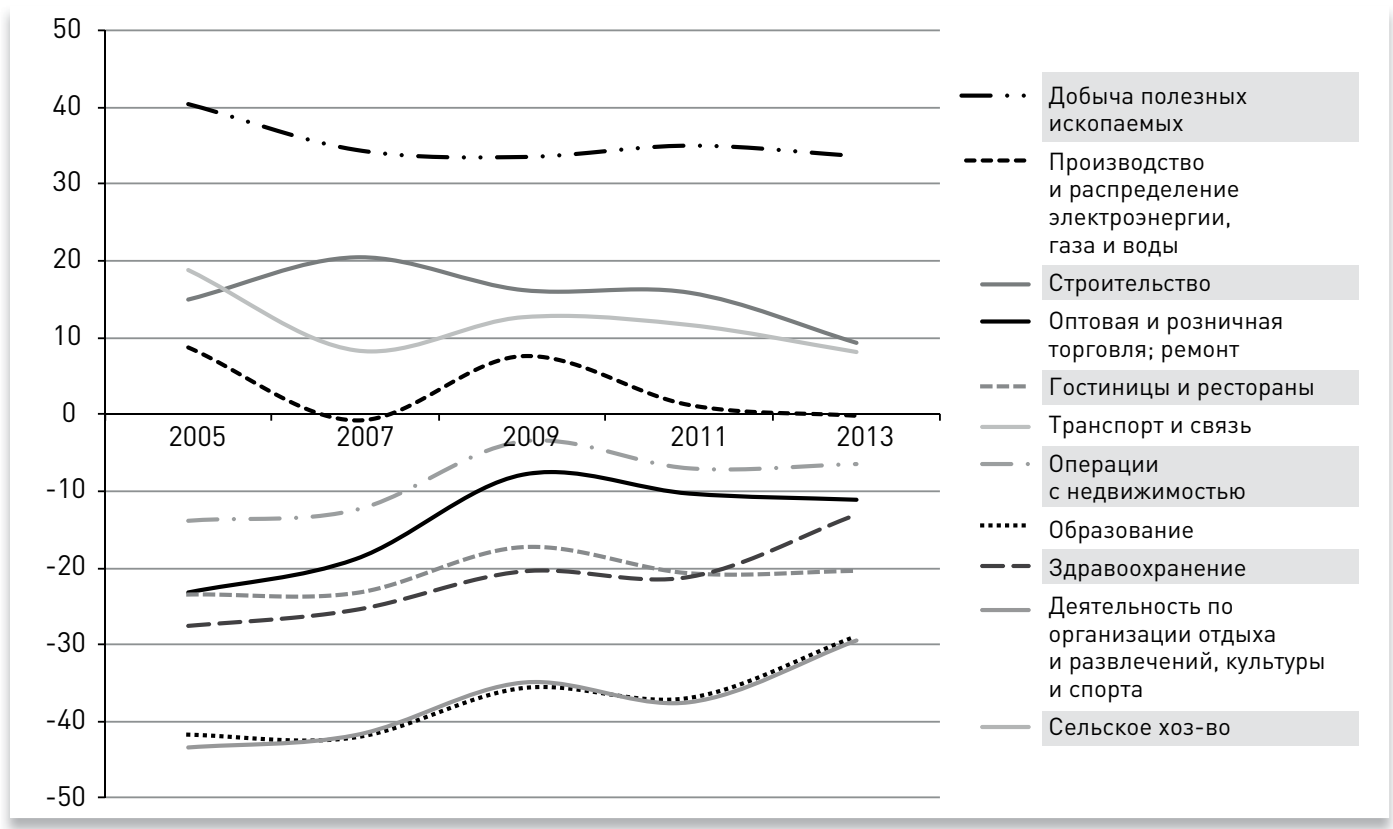

Рис. 5

Влияние отрасли (вида деятельности) на заработную плату, показатели, основанные на оценках стандартного уравнения заработной платы, \% к заработной плате в обрабатывающем производстве

Примечание. Эффекты влияния отраслей показаны в \% по отношению к обрабатывающим производствам $(D)$, оценки основаны на кроссекционных МНК-регрессиях, данные ОЗПП, $N=800$ тыс. Контролируются возраст и квадрат возраста, образование, логарифм отработанных часов. Государственное управление, финансы и сельское хозяйство (за исключением 2013 г.) исключены из обследования.

\footnotetext{
2 Это обследование проводится Росстатом. Справедливости ради следует отметить, что и стандартные данные о зара-
} ботной плате, регулярно публикуемые Росстатом, также ограничены кругом крупных и средних предприятий. 
Однако сокращение межотраслевого неравенства могло сопровождаться усилением внутриотраслевого. Этому вопросу посвящен следующий раздел.

\section{4. Внутриотраслевое неравенство}

Используя данные ОЗПП, мы можем также оценить внутриотраслевое неравенство и его изменения во времени. В табл. 1 представлены значения коэффициентов Джини для всех укрупненных видов деятельности, представленных в обследовании. Таблица свидетельствует о том, что внутриотраслевая дифференциация практически везде сокращалась. Это сокращение составляло от 0,01 до 0,03 п.п. значения коэффициента Джини. При этом наиболее заметно сокращение дифференциации внутри торговли (в классификаторе ОКВЭД она имеет код $\mathrm{G})$, где коэффициент Джини снизился с 0,46 до 0,40, или на 0,06 п.п. Это могло внести заметный вклад в общую дифференциацию, так как на сектор торговли приходится растущая доля общей занятости. Единственным исключением из тенденции является деятельность в области культуры (код 92), где коэффициент Джини вырос с 0,47 до 0,49, но доля сектора в общей занятости очень мала.

Все представленные выше данные свидетельствуют о том, что вклад отраслей в зарплатное неравенство последовательно

таблица 1

Внутриотраслевая дифференциация заработных плат, коэффициент Джини

\begin{tabular}{l|c|c}
\multicolumn{1}{c|}{ Вид деятельности } & \multicolumn{2}{c}{ Коэффициент Джини } \\
\cline { 2 - 3 } & 2005 г. & 2013 г. \\
\hline \hline Сельское хозяйство & - & 0,35 \\
\hline Добыча полезных ископаемых & 0,39 & 0,36 \\
\hline Обрабатывающие производства & 0,37 & 0,34 \\
\hline Производство и распределение электроэнергии, газа и воды & 0,35 & 0,34 \\
\hline Строительство & 0,39 & 0,35 \\
\hline Оптовая и розничная торговля; ремонт & 0,46 & 0,40 \\
\hline Гостиницы и рестораны & 0,40 & 0,37 \\
\hline Транспорт и связь & 0,38 & 0,35 \\
\hline Операции с недвижимым имуществом & 0,45 & 0,43 \\
\hline Образование & 0,40 & 0,38 \\
\hline Здравоохранение & 0,37 & 0,36 \\
\hline Деятельность по организации отдыха и развлечений, культуры & 0,47 & 0,49 \\
\hline и спорта & & \\
\hline
\end{tabular}

Источник: расчеты автора на основе ОЗПП за 2005 и 2013 г.

Таблица 2

Декомпозиция Филдса-Шоррокса, \% объясняемой вариации в логарифмах заработной платы и изменения во вкладах характеристик $(\Delta)$ между 2005 и 2013 г.

\begin{tabular}{l|c|c|c|c|c|c}
\hline \multirow{2}{*}{\multicolumn{1}{|c|}{ Показатель }} & \multicolumn{3}{|c|}{ Мужчины } & \multicolumn{3}{c}{ Женщины } \\
\cline { 2 - 7 } & 2005 г. & 2013 г. & $\Delta$ & 2005 г. & 2013 г. & $\Delta$ \\
\hline \hline Возраст & 1,0 & 1,1 & 0,2 & 1,1 & 0,7 & $-0,4$ \\
\hline Образование & 6,9 & 10,7 & 3,9 & 13,7 & 17,0 & 3,3 \\
\hline Регион & 15,7 & 16,7 & 1,0 & 16,7 & 18,2 & 1,7 \\
\hline $\begin{array}{l}\text { Отрасль (вид } \\
\text { деятельности) }\end{array}$ & 9,7 & 8,1 & $-1,6$ & 7,9 & 3,1 & $-4,8$ \\
\hline Рабочие часы & 0,6 & 1,0 & 0,4 & 0,2 & 0,6 & 0,4 \\
\hline Остаток & 66,3 & 62,4 & $-3,9$ & 60,5 & 60,3 & $-0,2$ \\
\hline
\end{tabular}

Источники: ОЗПП за 2005 и 2013 г. и расчеты автора. 
сокращался. Мы можем оценить это снижение, используя декомпозицию Филдса-Шоррокса и данные ОЗПП за 2005 и 2013 г. (Shorrocs, 1982; Fields, 2003). Эта декомпозиция показывает вклад каждого фактора в общую вариацию заработной платы, т.е. в неравенство. Результаты представлены в табл. 2.

Согласно данным, представленным в табл. 2, вклад отраслевого фактора в вариацию заработной платы у мужчин снизился с 9,7\% в 2005 г. до 8,1\% в 2013 г., или на 1,6 п.п. Соответствующее снижение у женщин было значительно больше и составило 4,8 п.п.: с 7,9\% в 2005 г. до 3,1\% в 2013 г. Больший масштаб снижения отраслевого вклада в дифференциацию у женщин можно объяснить ускоренным ростом оплаты труда в бюджетном секторе, где женщины преобладают. Одновременно увеличился вклад образования. Это неудивительно, так как работники бюджетного сектора имеют более высокий уровень образования.

\section{5. Вклад структуры заработной платы}

Дифференциация заработной платы зависит от ее гибкости, а важнейшим механизмом гибкости является использование переменной (премиально-бонусной) составляющей в оплате труда. Чем больше доля переменной части в структуре заработной платы, тем потенциально выше дифференциация в оплате. Это связано с тем, что неоднородность фирм и работников по производительности (и шире - по экономической результативности в целом) прямо транслируется в оплату труда, а институциональные возможности цензурировать складывающееся распределение в крайних (по результатам) отраслях ограничены. Таким образом, размер переменной части варьирует по отраслям/видам деятельности и отражает возможности получения в отрасли дополнительного дохода.

Ниже мы рассмотрим межотраслевую дифференциацию в переменной части заработной платы, используя для этого два источника данных, предоставляемых Росстатом.

О доле переменной части в оплате труда можно судить на основе данных обследования затрат труда. Такое обследование проводилось Росстатом в последний раз в 2013 г, до этого только в 2009 г. Однако 2009 г. был кризисным годом, в кризисы переменная часть заработной платы, как известно, сжимается, а доля тарифа и окладов возрастает. В 2013 г. острота кризиса прошла, но возврата к тенденциям, наблюдавшимся до 2008 г., не произошло, и после краткосрочного восстановления экономики началось новое замедление. Структура заработной платы инерционная, поэтому у нас есть все основания считать, что радикальных изменений здесь быть не могло. В табл. 3 представлены значения для доли постоянной части заработков (оплата по тарифным ставкам, окладам, сдельным расценкам) всего и за отработанное время, а также без учета и с учетом районного регулирования. Ниже приведены данные за 2009 г., поскольку они больше соответствуют ситуации 2015 г. (однако фактические различия между структурами заработной платы в 2009 и 2013 г. невелики).

Как нетрудно заметить, доля переменной части очень велика. Она максимальная в добывающих отраслях - лидерах по уровню оплаты труда, где с учетом районного регулирования и только за отработанное время она составляет почти $56 \%$. В то же время она минимальная в текстильном и швейном производстве - аутсайдерах по заработной плате, где она составляет около $24 \%$. Если же учесть неоднородность предприятий с точки зрения финансовых результатов, то вариация еще больше. Неудивительно, что это транслируется и в дифференциацию заработных плат.

На рис. 6 показана обратная взаимозависимость между долей переменной части (с учетом вклада региональных коэффициентов) в фонде оплаты труда и средней заработной платой в данном виде деятельности (значки на рисунке обозначают виды деятельности).

Вывод, который можно сделать на основе представленных данных, заключается в том, что доля переменной части в фонде оплаты возрастает по мере роста средней оплаты труда.

Данные ОЗПП позволяют также по-другому посмотреть на вклад отраслевой принадлежности в неравенство заработных плат. Здесь возникают два вопроса, какова диф-

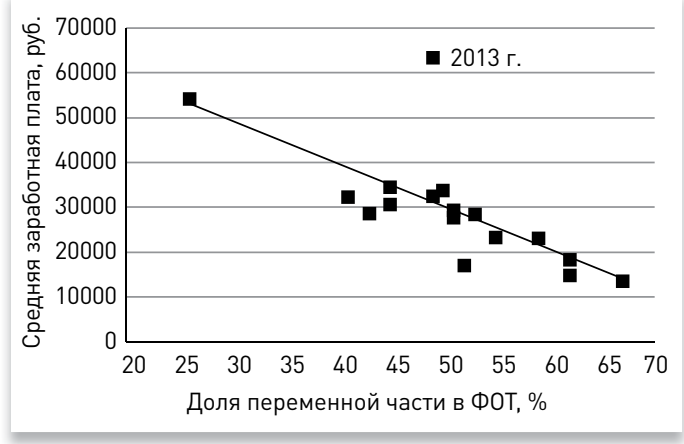

\section{Рис. 6}

Взаимосвязь структуры и уровня заработной платы, 2013 г. (точками обозначены виды деятельности)

Источники: данные Росстата и расчеты автора. 
Таблица 3

Доля постоянной части в структуре фонда оплаты труда (ФОТ) в 2009 г., \%

\begin{tabular}{|c|c|c|c|c|}
\hline \multirow[b]{2}{*}{ Деятельность } & \multicolumn{2}{|c|}{$\begin{array}{l}\text { Без учета районных } \\
\text { коэффициентов }\end{array}$} & \multicolumn{2}{|c|}{$\begin{array}{l}\text { С учетом районных } \\
\text { коэффициентов }\end{array}$} \\
\hline & 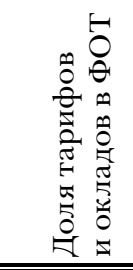 & 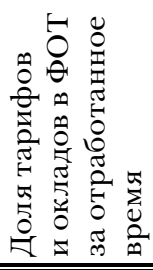 & 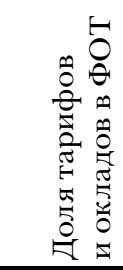 & 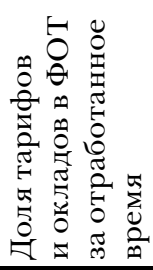 \\
\hline $\begin{array}{l}\text { Всего по обследованным видам экономиче- } \\
\text { ской деятельности }\end{array}$ & 47,6 & 56,9 & 52,5 & 62,8 \\
\hline Добыча полезных ископаемых & 25,9 & 33,9 & 33,5 & 43,8 \\
\hline Обрабатывающие производства & 49,1 & 58,7 & 52,9 & 63,3 \\
\hline \multicolumn{5}{|l|}{ Из них: } \\
\hline $\begin{array}{l}\text { - производство пищевых продуктов, включая } \\
\text { напитки, и табака }\end{array}$ & 54,5 & 62,6 & 57,4 & 66,0 \\
\hline - текстильное и швейное производство & 66,7 & 74,7 & 68,4 & 76,6 \\
\hline $\begin{array}{l}\text { - производство кожи, изделий из кожи и про- } \\
\text { изводство обуви }\end{array}$ & 61,5 & 68,6 & 63,5 & 70,8 \\
\hline $\begin{array}{l}\text { - обработка древесины и производство изде- } \\
\text { лий из дерева }\end{array}$ & 52,4 & 60,0 & 59,7 & 68,4 \\
\hline $\begin{array}{l}\text { - целлюлозно-бумажное производство, изда- } \\
\text { тельская и полиграфическая деятельность }\end{array}$ & 53 & 62,2 & 57,1 & 67,1 \\
\hline - химическое производство & 48,7 & 58,4 & 51,7 & 62,0 \\
\hline $\begin{array}{l}\text { - металлургическое производство и производ- } \\
\text { ство готовых металлических изделий }\end{array}$ & 42,8 & 52,2 & 47,4 & 57,8 \\
\hline - производство машин и оборудования & 49,1 & 58,1 & 53,8 & 63,7 \\
\hline $\begin{array}{l}\text { - производство электрооборудования, элек- } \\
\text { тронного и оптического оборудования }\end{array}$ & 50,5 & 58,9 & 53,6 & 62,5 \\
\hline $\begin{array}{l}\text { - производство транспортных средств } \\
\text { и оборудования }\end{array}$ & 44,5 & 56,2 & 48,2 & 60,9 \\
\hline $\begin{array}{l}\text { Производство и распределение электроэнер- } \\
\text { гии, газа и воды }\end{array}$ & 40,8 & 49,0 & 45,8 & 55,0 \\
\hline Строительство & 50,9 & 60,4 & 57,4 & 68,1 \\
\hline $\begin{array}{l}\text { Оптовая и розничная торговля; ремонт авто- } \\
\text { транспортных средств, мотоциклов, бытовых } \\
\text { изделий и предметов личного пользования }\end{array}$ & 58,9 & 67,9 & 62,1 & 71,5 \\
\hline Гостиницы и рестораны & 62,2 & 71,8 & 66,3 & 76,6 \\
\hline Транспорт и связь & 45 & 54,2 & 50,5 & 60,9 \\
\hline \multicolumn{5}{|l|}{ Из них: } \\
\hline - связь & 57,3 & 66,5 & 62,6 & 72,7 \\
\hline Финансовая деятельность & 49,2 & 59,7 & 51,9 & 63,0 \\
\hline $\begin{array}{l}\text { Операции с недвижимым имуществом, аренда } \\
\text { и предоставление услуг }\end{array}$ & 49,7 & 58,0 & 53,3 & 62,2 \\
\hline $\begin{array}{l}\text { Сбор сточных вод, отходов и аналогичная } \\
\text { деятельность }\end{array}$ & 52,4 & 59,8 & 56,9 & 64,9 \\
\hline
\end{tabular}

Источник: рассчитано автором по данным Росстата (http:/ / www.gks.ru/bgd/regl/B11_36/IssWWW.exe/Stg/d2/08-03.htm). 
ференциация внутри постоянной и переменной составляющих заработной платы? Как это деление влияет на общую дифференциацию? Поскольку доля переменной части в заработной плате сильно варьирует по отраслям, то и отраслевое деление также в итоге влияет на масштабы неравенства.

Используя данные ОЗПП, мы можем рассчитать коэффициенты Джини для постоянной и переменной частей заработной платы, а также оценить их вклады в общее наблюдаемое (на этой выборке) неравенство по заработной плате. Для этого используется декомпозиция коэффициента Джини по источникам доходов (Lerman, Yitzhaki, 1985; Lambert, Aronson, 1993). Поскольку обследование выделяет три источника, включая также районные коэффициенты (региональные надбавки), то мы распределяем последние между постоянной и переменной компонентами пропорционально их весу в заработной плате.

Декомпозиция имеет вид:

$$
G=\sum_{(k=1)}^{k} S_{k} G_{k} \mathbf{R}_{k},
$$

где $G$ - общий коэффициент Джини; $S_{k}-$ доля источника $k$ в общем доходе (заработной плате); $G_{k}-$ коэффициент Джини для источника $k ; R_{k}$ - корреляция между распределениями всего дохода и дохода из источника $k$. Результаты декомпозиции представлены в табл. 4.

Постоянная и переменная части заработной платы соотносятся как 2 : 1, но переменная часть, обычно связанная с результативностью организаций, отличается большей дифференциацией. Коэффициент Джини для нее составляет 0,63 против 0,41 - для постоянной части. Тем самым она вносит значительный вклад в формирование общего неравенства по заработной плате. Другими словами, чем больше доля переменной части в общей заработной плате в отрасли, тем больше общее неравенство.

Таблица 4

Декомпозиция неравенства по заработной плате в 2013 г.: вклад составляющих

\begin{tabular}{|c|c|c|c|c|c|}
\hline 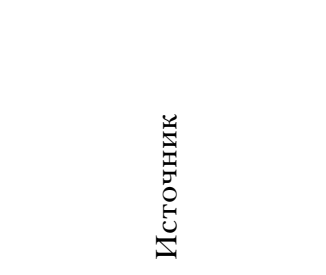 & 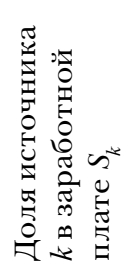 & 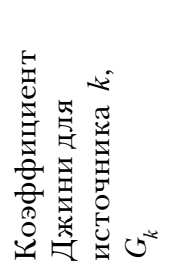 & 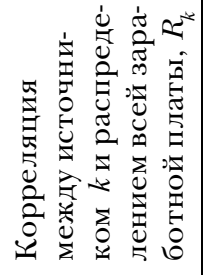 & 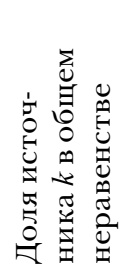 & 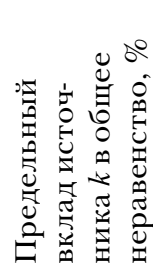 \\
\hline Постоянная часть & 0,6785 & 0,4059 & 0,8649 & 0,6157 & $-0,0628$ \\
\hline Переменная часть & 0,3215 & 0,6300 & 0,7342 & 0,3843 & 0,0628 \\
\hline Вся заработная плата & & 0,3869 & & & \\
\hline
\end{tabular}

Хотя переменная часть составляет в среднем $32 \%$ всей заработной платы, она объясняет $38,5 \%$ всей дифференциации. На долю постоянной части $(68 \%)$ приходится менее $62 \%$ общей величины коэффициента Джини. В итоге постоянная часть выравнивает заработки (предельный эффект влияния 1\% увеличения постоянной части составляет $-0,063 \%$ ), а переменная увеличивает дифференциацию. По сравнению с 2005 г. доля постоянной части несколько (на 2 п.п.) снизилась, но сократилось и неравенство, создаваемое переменной частью (с 0,69 до 0,63). В итоге предельный вклад каждого источника также несколько уменьшился. Таким образом, отрасли с большей переменной долей в заработной плате вносят больший вклад в общее неравенство. Здесь речь может идти прежде всего о добывающих отраслях, в которых постоянная часть составляет лишь около трети, и в несколько меньшей степени - о производстве и распределении электроэнергии, тепла и воды, а также о металлургическом производстве.

\section{Заключение}

В статье представлен взгляд на неравенство со стороны спроса на труд, хотя традиционно оно рассматривается со стороны предложения. Актуальность такого подхода объясняется значительной дифференциацией отраслей по уровню оплаты и отраслевыми особенностями процессов зарплатоообразования.

Наш анализ показывает, что изменения на рынке труда в период с 2005 по 2014 г. вели к тому, что межотраслевая дифференциация в оплате труда снижалась. Этому способствовали как сокращение занятости в наименее оплачиваемых видах деятельности, так и сокращение относительных заработных плат в отраслях с самой низкой и самой высокой оплатой труда. В итоге все большее число работников стягивалось к середине распреде- 
ления. В то же время сокращалась и внутриотраслевая дифференциация в оплате.

Важную роль в формировании дифференциации в оплате труда играет двухъярусная структура оплаты труда, т.е. деление всего заработка на постоянную и переменную части. В отсутствие переменной части дифференциация была бы значительно ниже, но вклад переменной части также медленно снижался. Влияние этого фактора варьирует по отраслям.

Каковы перспективы динамики межотраслевого неравенства в среднесрочной перспективе? По-видимому, оно продолжит сокращаться. Этому будут способствовать несколько обстоятельств. Снижение мировых цен на сырье и энергоносители будет отрицательно влиять на возможности соответствующих предприятий повышать оплату труда. Таким образом, относительная оплата в них продолжит снижаться, приближаясь к средней по экономике. То же самое, по-видимому, будет происходить и в финансовом секторе, на который серьезно повлиял текущий кризис. Однако если повышающее (или поддерживающее) давление на заработную плату в бюджетных отраслях не исчезнет, то относительные заработные платы в них будут расти, а доля в занятости падать. Это также создаст выравнивающий эффект.

\section{ЛИТЕРАТУРА}

Российский работник: образование, профессия, квалификация (2011). Под общ. ред. В.Е. Гимпельсона, Р.И. Капелюшникова. М.: Издательский дом НИУ ВШЭ.

Fields G.S. (2003). Accounting for Income Inequality and Its Change: A New Method, with Application to the Distribution of Earnings in the United States / / Research in labor economics. No. 22. P. 1-38.

Gimpelson V., Kapeliushnikov R. (2013). Labor Market Adjustment: Is Russia Different? In: "The Oxford Handbook of the Russian Economy”. S. Weber, M.V. Alexeev (eds.). Oxford: Oxford University Press.

Lambert P., Aronson R. (1993). Inequality Decomposition Analysis and the Gini
Coefficient Revisited // The Economic Journal. No. 103. P. 1221-1227.

Lerman R., Yitzhaki S. (1985). Income Inequality Effects by Income Source: A New Approach and Applications to the United States // Review of Economics and Statistics. Vol. 67. P. 151-156.

OECD (2011). OECD Reviews of Labour Market and Social Policies: Russian Federation. Paris: OECD.

Shorrocks A. (1982). Inequality Decomposition by Factor Components // Econometrica. Vol. 50(1). P. 193-211.

Поступила в редакиию 4 мая 2016 года

REFERENCES (with English translation or transliteration)

Fields G.S. (2003). Accounting for Income Inequality and Its Change: A New Method, with Application to the Distribution of Earnings in the United States. Research in labor economics 22, 1-38.

Gimpelson V., Kapeliushnikov R. (2013). Labor Market Adjustment: Is Russia Different? In: "The Oxford Handbook of the Russian Economy”. S. Weber, M.V. Alexeev (eds.). Oxford: Oxford University Press.

Lambert P., Aronson R. (1993). Inequality Decomposition Analysis and the Gini Coefficient Revisited. The Economic Journal 103, 1221-1227.

Lerman R., Yitzhaki S. (1985). Income Inequality Effects by Income Source: A New Approach and Applications to the United States. Review of Economics and Statistics 67, 151-156.

OECD (2011). OECD Reviews of Labour Market and Social Policies: Russian Federation. Paris: OECD.

Russian Worker: Education, Occupation, Skills (2011). V. Gimpelson, R. Kapeliushnikov (eds.). Moscow: National Research University Higher School of Economics (in Russian).

Shorrocks A. (1982). Inequality Decomposition by Factor Components. Econometrica 50(1), 193-211. 


\section{V.Ye. Gimpelson}

National Research University Higher School of Economics, Moscow, Russia

\section{Structural Change and Inter-Industry Wage Differentiation}

Abstract. The paper discusses how industrial division of the Russian economy affected wage inequality in the beginning of XXI century. This impact depended on the industrial composition of employment, industrial wage premiums, and intra-industry wage differentiation. Calculations based on various Rosstat data sources suggest that all three factors contributed to the narrowing of wage inequality. Proportion of employment in the highest and lowest paying industries tended to shrink, compressing the wage distribution from the both tales. Wages in these industries approached the averages for the whole economy. At the same time, the intra-industry wage differentiation measured by Gini coefficients contracted as well. Observed dynamics in cross-industrial inequality can survive in medium term perspective. Lower hydrocarbon prices are likely to affect negatively the wage paying capacity of firms in this sector, thus compressing relative wages. The same can happen in the crisisridden financial sector. If upward pressures on wages in the budgetary sector do not disappear, relative wages here will grow bringing an equalizing effect on the total wage distribution.

Keywords: wages, inequality, cross-industry differentiation.

JEL Classification: J21, J31. 